19,05

\title{
Влияние изовалентного замещения катионов на термические, калорические и магнетокалорические свойства манганитов $\left(\mathrm{La}_{1-y} \mathrm{Eu}_{y}\right)_{0.7} \mathrm{~Pb}_{0.3} \mathrm{MnO}_{3}$
}

\author{
(C) А.В. Карташев ${ }^{1,2}$, И.Н. Флёров ${ }^{1,3}$, М.В. Горев ${ }^{1,3}$, Н.В. Михашенок ${ }^{1}$ \\ ${ }^{1}$ Институт ффизики им. Л.В. Киренского СО РАН - обособленное подразделение ФИЦ КНЦ СО РАН, \\ Красноярск, Россия \\ ${ }^{2}$ Красноярский государственный педагогический университет им. В.П. Астафььева, \\ Красноярск, Россия \\ ${ }^{3}$ Институт инженерной физики и радиоэлектроники, Сибирский федеральный университет, \\ Красноярск, Россия \\ E-mail: akartashev@yandex.ru
}

(Поступила в Редакцию 25 июля 2018 г.)

Выращены кристаллические образцы твердых растворов манганитов $\left(\mathrm{La}_{1-y} \mathrm{Eu}_{y}\right)_{0.7} \mathrm{~Pb}_{0.3} \mathrm{MnO}_{3}(y: 0,0.2,0.4$, $0.5,0.6,0.8)$. Исследованы температурные зависимости теплоемкости, теплового расширения и интенсивного магнетокалорического эффекта. Выполнен сравнительный анализ влияния изовалентного катионного замещения на термические и калорические параметры ферромагнитного фазового перехода. Увеличение концентрации атомов Еu приводит к уменьшению энтропии фазового перехода и росту барического коэффициента $d T / d p$. Определены полевые и температурные зависимости магнетокалорического эффекта (MCE). Показано, что варьирование соотношения катионов позволяет получить твердые растворы с максимальной величиной МСЕ в полях до $6 \mathrm{kOe}$ в широкой области температур 90-340 К. В соответствии с близкими значениями приведенной относительной мощности охлаждения, исследованные твердые растворы могут служить в качестве модельных твердотельных хладагентов при проектировании каскадного охлаждения.

Исследование выполнено при финансовой поддержке Российского фонда фундаментальных исследований, Правительства Красноярского края, Красноярского краевого фонда науки в рамках научного проекта № 17-42-240076 „Комплексный подход к поиску и разработке перспективных ферроидных твердотельных хладагентов на основе моно- и мульти-калорических эффектов“.

DOI: 10.21883/FTT.2019.01.46914.221

\section{1. Введение}

В последнее время нарастает потребность в новых эффективных охлаждающих устройствах, конкурентоспособных по отношению к давно и широко используемым газокомпрессорным холодильным установкам. Среди прочих причин, объясняющих этот интерес, можно назвать экологические проблемы, связанные с использованием фреонов, потребность в миниатюризации рефрижераторов, необходимость увеличения удельной энергетической экономичности и холодопроизводительности и пр. Одним из наиболее перспективных и многообещающих является направление, связанное с разработкой рефрижераторов, в основе которых лежит использование калорических эффектов (электро-, баро- и магнетокалорического) в твердых телах, выражающихся в изменении температуры или энтропии материала при наложении/снятии внешнего поля - электрического, механических напряжений, магнитного [1-8]. Величины экстенсивного $\Delta S_{\mathrm{CE}}$ и интенсивного $\Delta T_{\mathrm{AD}}$ калорических эффектов пропорциональны температурным производным параметра порядка (поляризации, деформации, намагниченности) [1] и в связи с этим достигают максимальных величин в области фазовых переходов, имеющих место в ферроидных и мультиферроидных материалах.
Твердотельные хладагенты по сравнению с газовыми обладают рядом важных преимуществ: малым удельным объемом, более высокой экологической толерантностью и значительной энергетической эффективностью [1,9].

При исследовании калорических эффектов разной физической природы в твердых телах наибольшее внимание уделяется магнетокалорическому эффекту (MCE), что, скорее всего, обусловлено богатым разнообразием материалов магнитной природы и сравнительно легким их дизайном [10]. Наряду с созданием новых эффективных твердотельных хладагентов на основе МСЕ, до сих пор не снижается интерес к исследованию семейства манганитов на основе $\mathrm{LaMnO}_{3}$, имеющего перовскитоподобную структуру. Обычно твердые растворы манганитов со смешанной валентностью катионов синтезируются путем гетеровалентного замещения катиона $\mathrm{La}^{3+}$ на $\mathrm{Ca}^{2+}, \mathrm{Sr}^{2+}, \mathrm{Ba}^{2+}, \mathrm{Pb}^{2+}[11-15]$ и $\mathrm{Na}^{+}, \mathrm{Ag}^{+}, \mathrm{K}^{+}$[16-18]. Вследствие наличия в структуре двухвалентного/одновалентного катиона трехвалентное состояние части ионов $\mathrm{Mn}^{3+}$ изменяется на четырех/пятивалентное, что, согласно последним модельным представлениям [19] приводит, в свою очередь, к появлению ферромагнитного состояния. Известные к настоящему времени манганиты уступают соединениям на основе $\mathrm{Gd}$ и сплавам типа $\mathrm{Gd}_{5}\left(\mathrm{Si}_{X} \mathrm{Ge}_{1-X}\right)_{4}$ 
и $\mathrm{La}\left(\mathrm{Fe}_{x} \mathrm{Si}_{1-x}\right)$ [20] в плане максимальных величин калорических эффектов $\Delta S_{\mathrm{MCE}}$ и $\Delta T_{\mathrm{AD}}$. Но, во-первых, они характеризуются сравнимой относительной мощностью охлаждения (RCP) за счет широкого интервала температур, в котором наблюдается значительный MCE и, во-вторых, являются более дешевыми.

Увеличение концентрации замещающего катиона приводит к повышению устойчивости ферромагнитной фазы, в частности, это ярко проявляется в системе твердых растворов $\mathrm{La}_{1-x} \mathrm{~Pb}_{x} \mathrm{MnO}_{3} \quad\left(T_{C} \approx 170\right.$ и $350 \mathrm{~K}$ соответственно при $y=0.1$ и 0.3 ) [21]. Исследования влияния изовалентного замещения $\mathrm{La}^{3+}$ редкоземельными катионами на свойства манганитов $\left(\mathrm{La}_{1-y} \mathrm{Me}_{3+y}\right)_{0.7} \mathrm{Me}_{0.3}^{2+} \mathrm{MnO}_{3}$, выполненные в ряде работ [22-24], показали, что при этом происходит сильная дестабилизация ферромагнитной фазы, а степень понижения температуры перехода $T_{C}$ зависит от размера катиона-заместителя. Например, в соединениях $\left(\mathrm{La}_{1-y} \mathrm{Eu}_{y}\right)_{0.7} \mathrm{~Pb}_{0.3} \mathrm{MnO}_{3}$ (LEPM) $T_{C}$ понижается от 340 до $120 \mathrm{~K}$ при изменении концентрации катиона $\mathrm{Eu}^{3+}$ от 0 до 60\% [22]. Столь широкий интервал температур, в котором происходят фазовые переходы в твердых растворах LEPM, позволяет рассматривать их в качестве модельных твердотельных хладагентов, перспективных для использования в циклах каскадного охлаждении.

Необходимо отметить, что соединения LEPM испытывают фазовые переходы второго рода в отличие от родственных манганитов $\left(\mathrm{La}_{1-y} \mathrm{Me}_{y}^{3+}\right)_{0.7} \mathrm{Me}_{0.3}^{2+} \mathrm{MnO}_{3}$ $\left(\mathrm{Me}^{3+}: \mathrm{Pr}, \mathrm{Nd}, \mathrm{Gd}, \mathrm{Dy}, \mathrm{Tb} ; \mathrm{Me}^{2+}: \mathrm{Ca}^{2+}, \mathrm{Ba}^{2+}\right)[15,24]$ и многих другого сорта магнитных материалов [20] и, таким образом, удовлетворяют одному из базовых требований, предъявляемых к твердотельным хладагентам, связанным с отсутствием гистерезиса температуры перехода [25].

В настоящей работе исследован характер влияния соотношения концентраций катионов $\mathrm{Eu}^{3+}$ и $\mathrm{La}^{3+}$ на магнитно-тепловые свойства системы твердых растворов $\left(\mathrm{La}_{1-y} \mathrm{Eu}_{y}\right)_{0.7} \mathrm{~Pb}_{0.3} \mathrm{MnO}_{3}(y: 0,0.2,0.4,0.5,0.6,0.8)$ путем прямых измерений теплоемкости, теплового расширения и магнетокалорического эффекта.

\section{2. Образцы и методы исследований}

Кристаллические образцы $\left(\mathrm{La}_{1-y} \mathrm{Eu}_{y}\right)_{0,7} \mathrm{~Pb}_{0.3} \mathrm{MnO}_{3}$ выращивались методом спонтанной кристаллизации [19]. Смесь соединений $\mathrm{PbO}$ и $\mathrm{PbF}_{2}$ использовалась как растворитель и одновременно обеспечивала требуемое количество атомов $\mathrm{Pb}$ в кристаллах. Для получения поликристаллических образцов исходные монокристаллы растирались в агатовой ступке и прессовались в виде таблеток, которые подвергались обжигу при температуpe $600^{\circ} \mathrm{C}$ в течение $3 \mathrm{~h}$. Средний размер кристаллитов

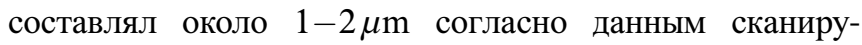
ющей электронной микроскопии. Состав полученных кристаллов был подтвержден рентгенофлуоресцентным анализом. Идентификация фаз и определение параметров решетки проведены с помощью рентгеновского порошкового дифрактометра D8 ADVANCE „Brucker“. Из анализа рентгенограмм следует, что кристаллы являются однофазными. Все дифрактограммы твердых растворов $\mathrm{c}^{3+}$ соответствуют искаженной структуре типа перовскита с пространственной группой $P 4 / m$, тогда как исходное соединение $\mathrm{La}_{0.7} \mathrm{~Pb}_{0.3} \mathrm{MnO}_{3}$ имеет ромбоэдрическую структуру (пр. гр. $R 3 c$ ).

Наиболее удобным инструментом для исследования теплоемкости и магнетокалорического эффекта является адиабатический калориметр, позволяющий получать информацию об этих свойствах в параллельных экспериментах на одном образце. В настоящей работе использован автоматизированный калориметр, конструкция которого подробно описана в [26].

Исследования теплоемкости $C_{p}(T)$ выполнены методами дискретных (с шагом $1-3 \mathrm{~K}$ ) и непрерывных $(d T / d t \approx 0.01-2.0 \mathrm{~K} / \mathrm{min})$ нагревов в температурном диапазоне 90-370 К. Погрешность определения теплоемкости не превышала $0.5-1.0 \%$. Образцы помещались в измерительную ячейку, и фиксировались с помощью смазок ApiezonN и ApiezonH, обеспечивающих надежный тепловой контакт. В области температур ниже $90 \mathrm{~K}$ измерения теплоемкости ряда образцов проведены на универсальной установке для измерения физических свойств PPMS (Quantum design).

Исследования магнетокалорического эффекта выполнялись по ранее разработанной методике в режимах наложения и снятия магнитного поля в области температур выше и ниже температуры фазового перехода [26]. При определенной температуре адиабатический калориметр настраивался так, чтобы дрейф температуры образца был в пределах $d T / d t \leq\left|10^{-3}\right| \mathrm{K} / \mathrm{min}$, как минимум, в течение часа и близким к линейному. Такое поведение температуры означало, что в криостате реализованы условия, максимально близкие к адиабатным: система стабилизирована и находится в устойчивом динамическом равновесии. В этом случае максимальная чувствительность к изменению температуры образца составляла не хуже $10^{-4} \mathrm{~K}$, в то время как абсолютная погрешность измерения температуры $\pm 10^{-2} \mathrm{~K}$ была ограничена параметрами использованных в криостате платиновых термометров.

При наложении (снятии) магнитного поля в магнитном материале выделяется (поглощается) теплота, которая расходуется на изменение температуры всей системы (образец + ячейки + смазка), на которой проводятся измерения. Таким образом, в экспериментах с варьированием магнитного поля измеряется величина $\Delta T_{\text {exp }}$, которая меньше действительной величины $\Delta T_{\mathrm{AD}}$, соответствующей интенсивному MCE в образце LEPM. Соотношение между этими температурными эффектами описывается следующим уравнением:

$$
\Delta T_{\mathrm{AD}}=\Delta T_{\exp }\left(1+\frac{C_{\text {cell }}+C_{\mathrm{Ap}}}{C_{\text {sample }}}\right),
$$

где $C_{\text {cell }}, C_{\text {Ap }}$ и $C_{\text {sample }}$ соответственно теплоемкости ячейки, смазки и образца. 
Дилатометрические исследования проводились на поликристаллических образцах с размерами $L=$ $=1.5-3.0 \mathrm{~mm}$ на индукционном дилатометре DIL-402C фирмы NETZSCH в потоке сухого газообразного гелия. Скорости нагрева образца в интервале температур 100-500 K варьировались от 2 до $4 \mathrm{~K} / \mathrm{min}$. Эталон из плавленого кварца был использован для калибровки и учета расширения измерительной системы. Данные, полученные в нескольких сериях измерений, согласовывались между собой в пределах $2-5 \%$.

\section{3. Экспериментальные результаты и обсуждение}

Результаты калориметрических исследований в широком интервале температур представлены в виде удельных теплоемкостей твердых растворов LEPM на рис. 1, $a$, которые вне аномальных температурных областей практически совпадают.

Вследствие небольшого различия атомных масс лантана и европия отличие молярных масс твердых растворов, при варьировании у от 0 до 0.8 , и соответственно молярных теплоемкостей оказывается очень небольшим $\sim 3 \%$. В выбранном на рис. 1, $a$ масштабе наиболее наглядно выглядят аномалии $C_{P}(T)$, связанные с переходом между парамагнитной и ферромагнитной фазами в соединениях $\left(\mathrm{La}_{1-y} \mathrm{Eu}_{y}\right)_{0.7} \mathrm{~Pb}_{0.3} \mathrm{MnO}_{3}$ с $y=0,0.2,0.5$. $\mathrm{B}$ такой ситуации наиболее информативными являются аномальные вклады $\Delta C_{p}(T)$ в теплоемкость, для выделения которых теплоемкость твердых растворов вдали от $T_{C}$ рассматривается как регулярный/решеточный вклад

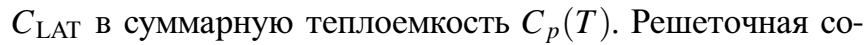
ставляющая для каждого твердого раствора была определена путем интерполяции данных в индивидуальных интервалах температур комбинацией функций Дебая и Эйнштейна. Для всех составов зависимость $C_{\mathrm{LAT}}(T)$ была идентичной с близкими значениями температур Дебая и Эйнштейна: $\Theta_{\mathrm{D}} \approx 213 \mathrm{~K}$ и $\theta_{\mathrm{E}} \approx 525 \mathrm{~K}$. Выделение аномальной теплоемкости $\Delta C_{P}(T)=C_{P}(T)-C_{\mathrm{LAT}}(T)$ (рис. $1, b)$, позволило определить для каждого из составов LEPM температуры максимумов $\Delta C_{p}(T)$, принимаемые за температуры фазовых переходов (таблица).

Из рис. $1, b$ видно, что рост концентрации $\mathrm{Eu}^{3+}$ приводит к размытию пика теплоемкости и значительному уменьшению его максимальной величины: $\Delta C_{p}$

Некоторые термодинамические параметры фазового перехода в твердых растворах $\left(\mathrm{La}_{1-y} \mathrm{Eu}_{y}\right)_{0.7} \mathrm{~Pb}_{0.3} \mathrm{MnO}_{3}$

\begin{tabular}{l|c|c|c}
\hline$y$ & $T_{C}, \mathrm{~K}$ & $\Delta H, \mathrm{~J} / \mathrm{g}$ & $d T / d p, \mathrm{~K} / \mathrm{kbar}$ \\
\hline 0 & 339 & 4.70 & 0.8 \\
0.2 & 287 & 2.60 & 1.0 \\
0.5 & 172 & 0.70 & 1.6 \\
0.6 & 120 & 0.63 & 2.3 \\
0.8 & 90 & 0.44 & -
\end{tabular}

от $90 \mathrm{~mJ} / \mathrm{g} \cdot \mathrm{K}$ при $y=0$ до $7 \mathrm{~mJ} / \mathrm{g} \cdot \mathrm{K}-y=0.8$. $\mathrm{B}$ соответствии с этим энтальпии фазовых переходов $\Delta H$, определенные путем интегрирования площади под пиком $\Delta C_{p}(T)$, также подвержены существенному уменьшению (таблица). Однако аномальные энтропии, связанные с фазовым переходом и определяемые комбинацией соотношений между теплоемкостью, энтальпией
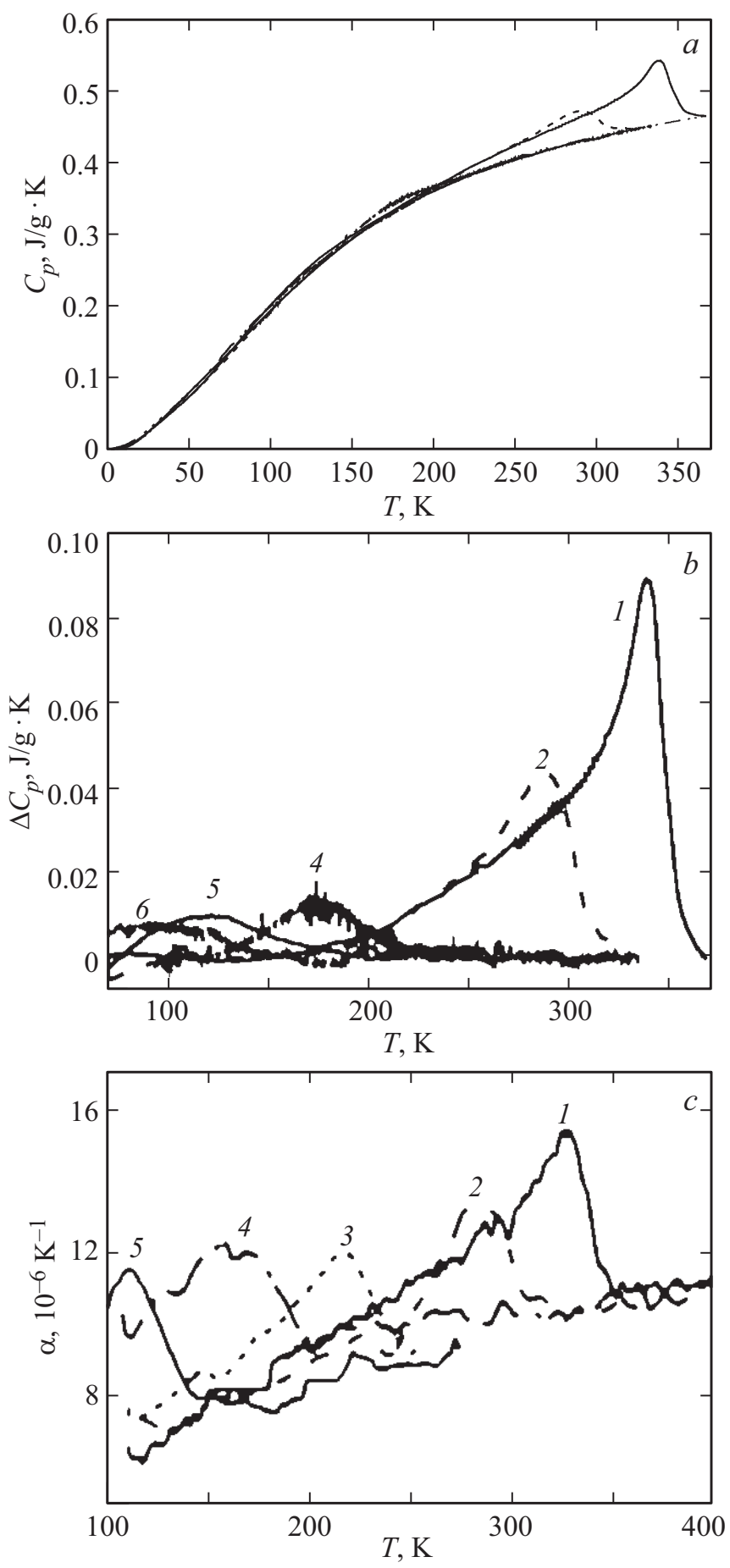

Рис. 1. Температурные зависимости удельной $(a)$, аномальной $(b)$ теплоемкости и коэффициента линейного теплового расширения (c) твердых растворов $\left(\mathrm{La}_{1-y} \mathrm{Eu}_{y}\right)_{0.7} \mathrm{~Pb}_{0.3} \mathrm{MnO}_{3}$ : $y=0.0(1) ; 0.2(2) ; 0.4(3) ; 0.5(4) ; 0.6(5)$ и $0.8(6)$. 

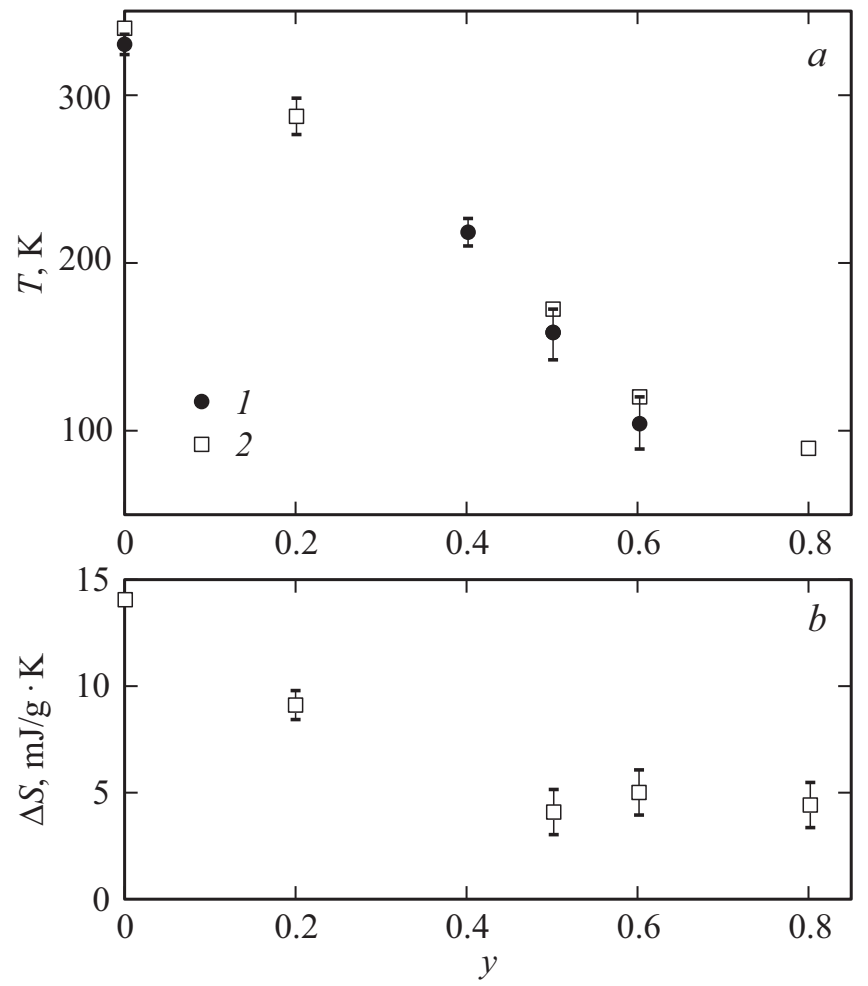

Рис. 2. Зависимости температуры $(a)$ и энтропии $(b)$ фазового перехода от концентрации катиона $\mathrm{Eu}^{3+}$.

и температурой перехода $\Delta S=\int\left(\Delta C_{p} / T\right) d T \approx \Delta H / T_{C}$, оказались менее чувствительными к изовалентному катионному замещению. Более того, величина $\Delta S$ уменьшается в $\sim 3.5$ раза лишь при росте у от 0 до 0.5 , а при дальнейшем увеличении концентрации $\mathrm{Eu}^{3+}$ остается практически постоянной в пределах погрешности ее определения. Это обстоятельство связано с резким уменьшением температуры перехода (рис. 2,a).

Уменьшение энтропии фазового перехода можно объяснить в приближении термодинамической теории [27], в соответствии с которой эта величина пропорциональна квадрату параметра порядка (намагниченности в случае LEPM) $\Delta S(T)=A_{T} M^{2}(T)$. Здесь $A_{T}-$ один из коэффициентов термодинамического потенциала $\Delta \Phi=A_{T} M^{2}+B M^{2}+C M^{2}+\ldots+H M$, определяемый производной от обратной магнитной восприимчивости $d \chi^{-1} / d T$. Согласно [19] для твердого раствора с $y=0.6$ величина $M$ примерно в два раза меньше по сравнению c $\mathrm{La}_{0.7} \mathrm{~Pb}_{0.3} \mathrm{ZMnO}_{3}$, что должно привести к уменьшению энтропии в четыре раза, которое близко к наблюдавшемуся нами изменению $\Delta S$ (рис. $2, b)$.

Температурные зависимости коэффициента линейного теплового расширения твердых растворов $\alpha(T)$ представлены на рис. 1, c. Из-за малых линейных размеров образцов ошибка измерений оказалась довольно большой 5-10\%. Для каждого из составов LEPM обнаружена одна небольшая аномалия $\alpha(T)$, температура максимума которой, принимаемая за температуру фазового перехода, уменьшается при увеличении $y$. В соответствии с концентрационной фазовой диаграммой характер зависимостей $T_{C}(y)$, определенных в калориметрических и дилатометрических экспериментах, полностью идентичен (рис. 1,c), что свидетельствует о высокой надежности данных, полученных разными методами.

Из зависимостей $\alpha(T)$ (рис. $1, c)$ следует, что в отличие от теплоемкости $\Delta C_{p}$, величины аномалий коэффициента теплового расширения весьма мало меняются с изменением соотношения между концентрациями лантана и европия. Положительный знак аномалий $\alpha$ свидетельствует о том, что при переходе в парамагнитную фазу объем увеличивается.

Фазовый переход в твердых растворах LEPM является типичным превращением второго рода. В связи с этим, используя уравнение Эренфеста $d T_{C} / d p=T_{C}\left(\Delta \beta / \Delta C_{p}\right)$, подробные калориметрические и дилатометрические данные, а также принимая, что $\Delta \beta=3 \Delta \alpha$, можно получить информацию о восприимчивости соединений к внешнему гидростатическому давлению. Рассчитанные величины начального сдвига температуры фазового перехода под гидростатическим давлением, представленные в таблице, свидетельствуют об увеличении барического коэффициента с ростом концентрации $\mathrm{Eu}^{3+}$.

Результаты одной из серий измерений интенсивного MCE, выполненных в парамагнитной фазе в окрестности $290 \mathrm{~K}$ на образце с $y=0.2$ в магнитных полях от 1 до $6 \mathrm{kOe}$, показаны на рис. 3, $а$. Средняя скорость изменения температуры, связанного с собственным температурным
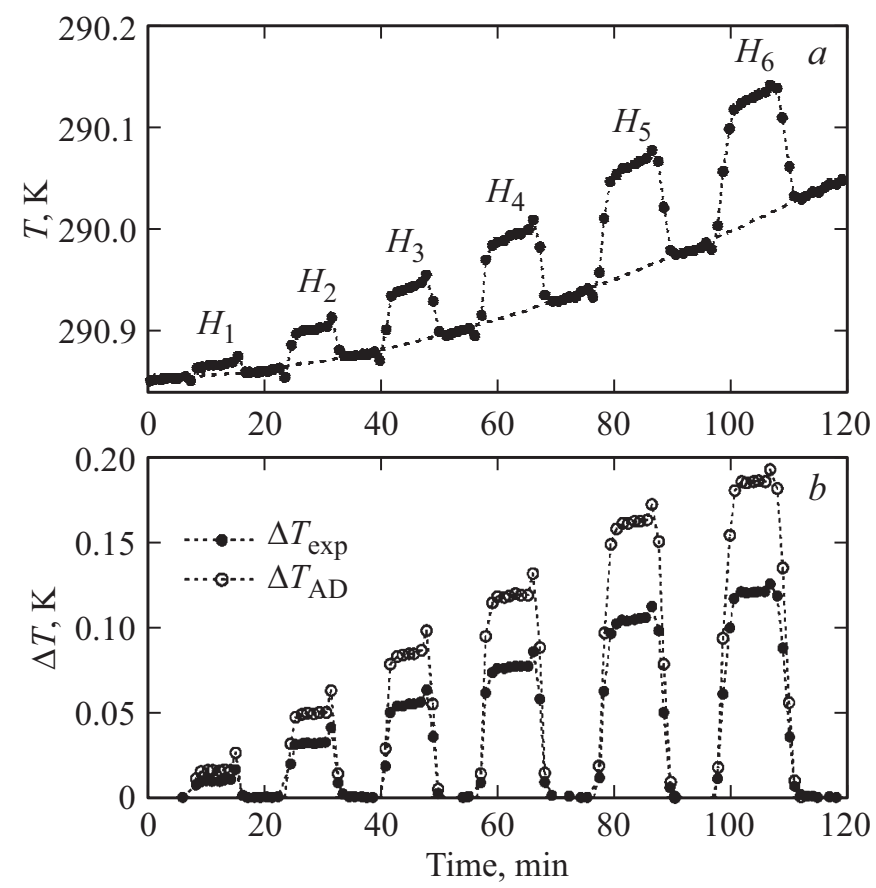

Рис. 3. Зависимость температуры образца $\left(\mathrm{La}_{0.8} \mathrm{Eu}_{0.2}\right)_{0.7} \mathrm{~Pb}_{0.3} \mathrm{MnO}_{3} \quad(a)$ и интенсивного магнетокалорического эффекта $\Delta T_{\mathrm{AD}}(b)$ от времени при включении и выключении магнитного поля: $H_{1}=1.2 \mathrm{kOe}, H_{2}=2.2 \mathrm{kOe}$, $H_{3}=3.3 \mathrm{kOe}, H_{4}=4.1 \mathrm{kOe}, H_{5}=5.4 \mathrm{kOe}, H_{6}=6.0 \mathrm{kOe}$. 
ходом калориметра, за время эксперимента (120 min), составляла $d T / d t \approx 7 \cdot 10^{-4} \mathrm{~K} / \mathrm{min}$.

Очевидно, что исследуемому твердому раствору свойственен заметный интенсивный магнетокалорический эффект - включение (выключение) магнитного поля сопровождается надежно регистрируемым увеличением (уменьшением) температуры системы образец + ячейка + смазка. Степень обратимости МСЕ оказалась весьма высокой - после выключения магнитного поля температура системы возвращается на ожидаемый уровень, получаемый экстраполяцией температурного хода $d T / d t$ из области температур, предшествующей включению поля.

В момент включения и выключения магнитного поля наблюдаются резкие скачкообразные изменения („всплески“) температуры, имеющие обратный знак по отношению к знаку МСЕ и связанные с наводками ЭДС-индукции на высокочувствительный усилитель сигнала термопары в цепи терморегулирования. Постоянство величины температурного хода $d T / d t$ в условиях $H=0$ и $H \neq 0$ свидетельствует о том, что этот эффект ни в коей мере не оказывает влияния на надежность регулирования адиабатических условий. Эксперименты, выполненные при этих же температурах в магнитных полях противоположного направления, показали неизменность знака и величины как интенсивного МСЕ, так и температурных „всплесков“, что подтверждает их нефизическую природу.

Рис. $3, b$ демонстрирует соотношение между экспериментально зафиксированными изменениями температуры $\left(\Delta T_{\text {exp }}\right)$ и скорректированными с учетом соотношения (1) величинами $\mathrm{MCE}\left(\Delta T_{\mathrm{AD}}\right)$.

Аналогичным образом были выполнены измерения интенсивного MCE для других составов LEPM в окрестностях индивидуальных фазовых переходов. Температурные зависимости $\Delta T_{\mathrm{AD}}$ в магнитных полях $3.2,4.1$ и $4.8 \mathrm{kOe}$ для исследованных твердых растворов показаны на рис. 4.

Следует отметить своеобразный характер изменения $\Delta T_{\mathrm{AD}}$ при увеличении концентрации $\mathrm{Eu}^{3+}$. За резким уменьшением максимального интенсивного МСЕ в соединении с $y=0.2$ по сравнению с $\mathrm{La}_{0.7} \mathrm{~Pb}_{0.3} \mathrm{MnO}_{3}$ следует незначительное изменение его величины в других твердых растворах. Однако для твердого раствора с $y=0.8$ величина $\Delta T_{\mathrm{AD}}^{\mathrm{MAX}}$ оказалась на $\sim 20 \%$ больше, чем для состава с $y=0.6$, и наблюдалась в более узком интервале температур (рис. 4). Причина наблюдаемых особенностей может быть связана с тем, что интенсивный МСЕ определяется соотношением между температурой, теплоемкостью и температурной производной намагниченности [1]

$$
\Delta T_{\mathrm{AD}}=-\frac{T}{C_{p}}\left(\frac{\partial M}{\partial T}\right)_{H} d H .
$$

Очевидно, что на комбинацию этих величин может оказывать существенное влияние качество образцов, которое в случае твердых растворов в значительной мере

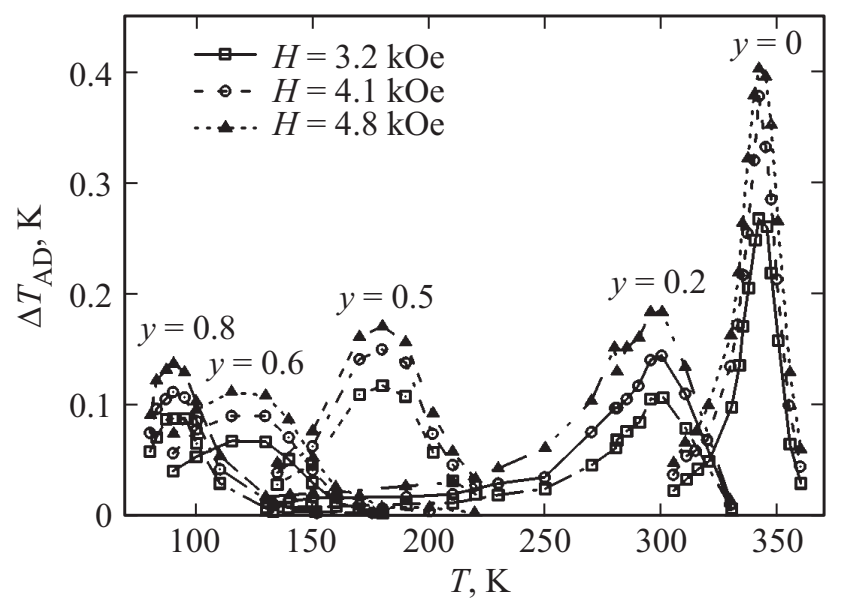

Рис. 4. Температурные зависимости интенсивного магнетокалорического эффекта $\Delta T_{\mathrm{AD}}$ в манганитах $\left(\mathrm{La}_{1-y} \mathrm{Eu}_{y}\right)_{0.7} \mathrm{~Pb}_{0.3} \mathrm{MnO}_{3}$ при различных напряженностях магнитного поля.

определяется однородностью упорядочения замещающего катиона $\mathrm{Eu}^{3+}$ в кристаллической решетке манганита. Из уравнения (2) также следует, что при определенных условиях зависимость $\Delta T_{\mathrm{AD}}(H)$ может быть близка к линейной, что видно на рис. $5, a$.

Однако более информативной является полевая зависимость приведенной величины $\left(\Delta T_{\mathrm{AD}} / H\right)(H)$ (рис. $\left.5, b\right)$. Видно, что влияние коэрцитивного поля значительно уменьшается в твердых растворах $(\sim 1 \mathrm{kOe})$ по сравнению с $\mathrm{La}_{0.7} \mathrm{~Pb}_{0.3} \mathrm{MnO}_{3}(3 \mathrm{kOe})$.

Эффективность магнитного хладагента определяется не только величиной абсолютного МСЕ, но и температурными интервалами, в которых присутствуют сравнительно большие величины $\Delta T_{\mathrm{AD}}$ и $\Delta S_{\mathrm{MCE}}$. В связи с этим наиболее объективными параметрами для сравнения эффективности различных магнетокалорических материалов являются интегральные характеристики относительные мощности охлаждения (RCP) [1]

$$
\begin{aligned}
& \operatorname{RCP}(T)=\Delta T_{\mathrm{AD}}^{\max } \delta T_{\mathrm{FWHM}}, \\
& \operatorname{RCP}(S)=\Delta S_{\mathrm{MCE}}^{\max } \delta T_{\mathrm{FWHM}},
\end{aligned}
$$

где $\Delta T_{\mathrm{AD}}^{\max }, \Delta S_{\mathrm{MCE}}^{\max }$ максимальные величины интенсивного и экстенсивного MCE, а $\delta T_{\mathrm{FWHM}}$ - полная ширина на половине высоты $\Delta T_{\mathrm{AD}}^{\max }(T)$ и $\Delta S_{\mathrm{MCE}}^{\max }(T)$.

Полевые зависимости относительных мощностей охлаждения, отнесенных к величине поля $\operatorname{RCP}(T) / H$ и $\operatorname{RCP}(S) / H$, приведены на рис. $5, c$ и $5, d$. Наиболее эффективным хладагентом оказался твердый раствор с $y=0.5$, для которого параметры $\mathrm{RCP} / H$ на $30 \%$ выше по сравнению с $\mathrm{La}_{0.7} \mathrm{~Pb}_{0.3} \mathrm{MnO}_{3}$ и твердыми растворами с $y=0.2$ и 0.6. Благодаря широкому интервалу температур, в котором существуют близкие по значениям величины $\Delta T_{\mathrm{AD}}^{\max }$, и небольшим напряженностям магнитного поля, приводящим к практически постоянным значениям $\operatorname{RCP}(T) / H$ и $\operatorname{RCP}(S) / H$, система твердых растворов 

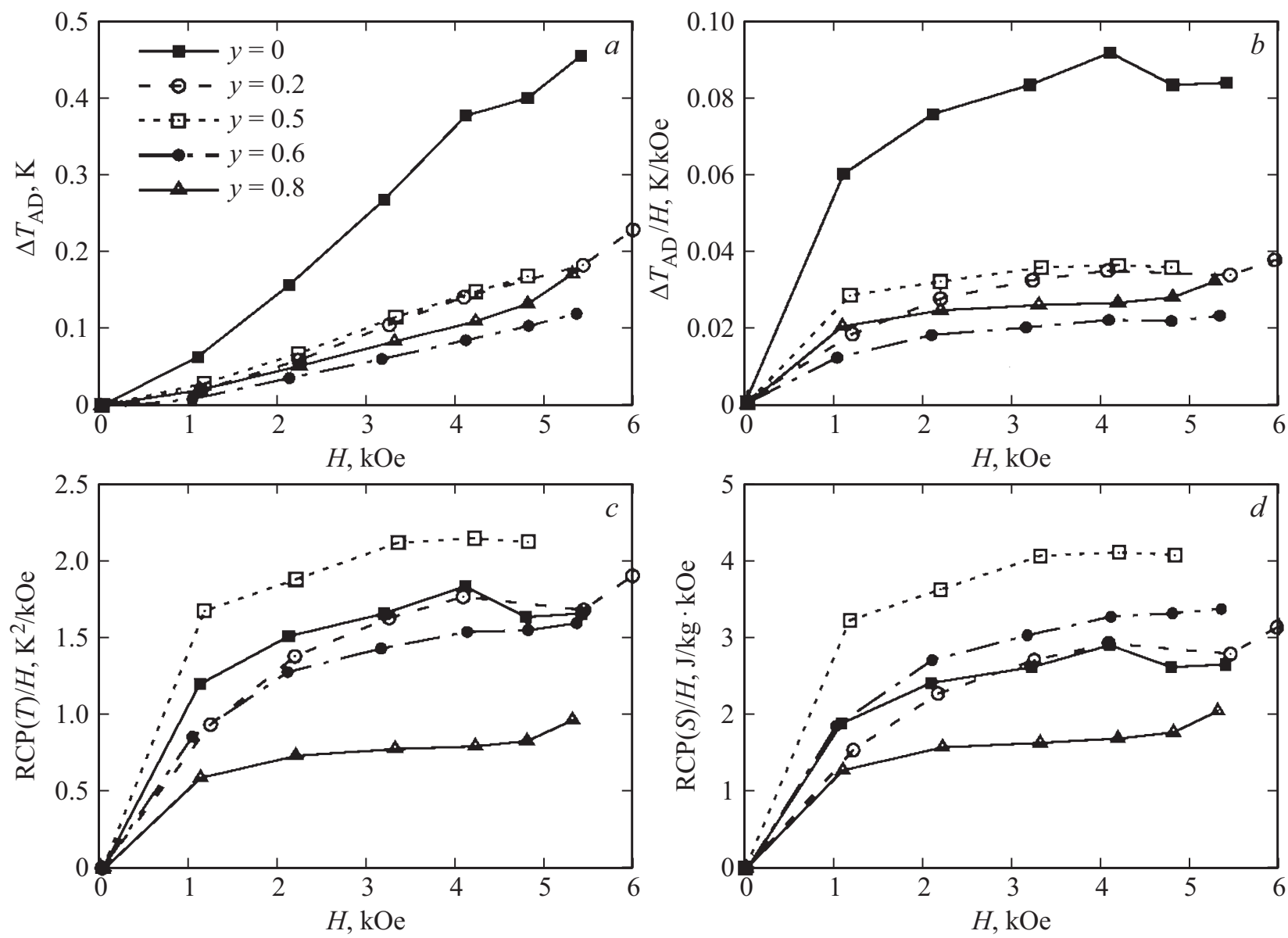

Рис. 5. Зависимости от магнитного пола абсолютных и приведенных величин: интенсивного $\Delta T_{\mathrm{AD}}(a)$ и $\Delta T_{\mathrm{AD}} / H(b)$ магнетокалорического эффекта и приведенной относительной мощности охлаждения $\operatorname{RCP}(T) / H(c)$ и $\operatorname{RCP}(S) / H(d)$.

$\left(\mathrm{La}_{1-y} \mathrm{Eu}_{y}\right)_{0.7} \mathrm{~Pb}_{0.3} \mathrm{MnO}_{3}$ может рассматриваться в качестве модельной при проектировании циклов каскадного охлаждения на основе твердотельных хладагентов.

\section{4. Заключение}

Выполнены исследования влияния изовалентного катионного замещения на теплоемкость, тепловое расширение, МCE и RCP твердых растворов манганитов $\left(\mathrm{La}_{1-y} \mathrm{Eu}_{y}\right)_{0.7} \mathrm{~Pb}_{0.3} \mathrm{MnO}_{3}$ ( $\left.y: 0,0.2,0.4,0.5,0.6,0.8\right)$.

Обнаружено значительное снижение температуры ферромагнитного фазового перехода и существенное уменьшение максимумов аномалий теплоемкости при увеличении концентрации катиона $\mathrm{Eu}^{3+}$. Аномалии коэффициента теплового расширения меняются в значительно меньшей степени, что в соответствии с уравнением Эренфеста приводит к росту восприимчивости твердых растворов к гидростатическому давлению.

Несмотря на значительное уменьшение энтальпии фазового перехода при изменении у от 0 до 0.8 , энтропия твердых растворов оказалась менее чувствительной к катионному замещению и при $y \geq 0.5$ остается практиче- ски неизменной, что обусловлено резким уменьшением температуры перехода.

Варьирование соотношения катионов $\mathrm{Eu}^{3+} / \mathrm{La}^{3+}$ от 0 до 0.8 позволяет получить твердые растворы с максимальной величиной МСЕ в очень широкой области температур - от $340 \mathrm{~K}$ до $90 \mathrm{~K}$.

В соответствии с близкими значениями абсолютных величин $\Delta T_{\mathrm{AD}}^{\max }$ при одном и том же поле для твердых растворов с $y=0.2-0.8$ и постоянными значениями $\operatorname{RCP}(T) / H$ и $\operatorname{RCP}(S) / H$, реализуемыми при невысоких полях, система твердотельных хладагентов $\left(\mathrm{La}_{1-y} \mathrm{Eu}_{y}\right)_{0.7} \mathrm{~Pb}_{0.3} \mathrm{MnO}_{3}$ может быть рекомендована в качестве исходной для моделирования циклов каскадного охлаждения.

Авторы признательны М.С. Молокееву за структурную характеризацию образцов.

\section{Список литературы}

[1] A.M. Tishin, Y.I. Spichkin. The Magnetocaloric Effect and its Applications. Institute of Physics Publishing, Bristol and Philadelphia (2003). 475 p. 
[2] L. Mañosa, A. Planes, M. Acet. J. Mater. Chem. A 1, 4925 (2013).

[3] P. Blumenthal, C. Molin, S. Gebhardt, A. Raatz. Ferroelectrics 497, 1 (2016).

[4] M. Ožbolt, A. Kitanovski, J. Tušek, A. Poredoš. Int. J. Refrigeration 37, 16 (2014).

[5] M. Ožbolt, A. Kitanovski, J. Tušek, A. Poredoš. Int. J. Refrigeration 40, 174 (2014).

[6] G. Suchaneck, G. Gerlach. Phase Transitions 88, 333 (2015).

[7] S. Qian, Y. Geng, Y. Wang, J. Ling, Y. Hwang, R. Radermacher, I. Takeuchi, J. Cui. Int. J. Refrigeration. 64, 1 (2016).

[8] L. Mañosa, A. Planes. Adv. Mater. 29, 1603607 (2017).

[9] K.A. Gschneider, V.K. Pecharsky. Ann. Rev. Mater. Sci. 30, 387 (2000).

[10] N.A. Zarkevich, D.D. Johnson, V.K. Pecharsky. J. Phys. D 51, 024002 (2018).

[11] J. Gutiérrez, J.R. Fernández, J.M. Barandiarán, I. Orúe, L. Righi. Sensors Actuators A 142, 549 (2007).

[12] M.A. Hamad. J. Therm Anal Calorim. 111:1251 (2013).

[13] M.H. Phan, S.C. Yu. J. Magn. Magn. Mater. 308, 325 (2007).

[14] X. Moya, L.E. Hoes, F. Maccherozzi, A.I. Tovstolytkin, D.I. Podyalovskii, C. Ducati, L.C. Phillips, M. Ghidini1, O. Hovorka, A. Berger, M.E. Vickers, E. Defay, S.S. Dhesi, N.D. Mathur. Nature Mater. 12, 52 (2013).

[15] R. Cherif, E.K. Hlil, M. Ellouze, F. Elhalouani, S. Obbade. J. Mater. Sci. 49, 8244 (2014).

[16] W. Chen, W. Zhong, D.L. Hou, R.W. Gao, W.C. Feng, M.G. Zhu, Y.W. Du. J. Phys.: Condens. Matter. 1411889 (2002).

[17] Z.M. Wang, T. Tang, Y.P. Wang, S.Y. Zhang, Y.W. Du. J. Magn. Magn. Mater. 246, 254 (2002).

[18] А.Г. Гамзатов, А.М. Алиев, И.К. Камилов, А.Р. Кауль. ФТТ 58, 1303 (2016).

[19] N. Volkov, G. Petrakovskii, P. Böni, E. Clementyev, K. Patrin, K. Sablina, D. Velikanov, A. Vasiliev. J. Magn. Magn. Mater. 309, 1 (2007).

[20] K.A. Gschneidner Jr., V.K. Pecharsky, A.O. Tsokol. Rep. Prog. Phys. 68, 1479 (2005).

[21] S.G. Min, K.S. Kim, S.C. Yu, H.S. Suh, S.W. Lee. IEEE Transact. Magn. 40, 2760 (2005).

[22] N. Volkov, G. Petrakovskii, K. Patrin, K. Sablina, E. Eremin, V. Vasiliev, A. Vasiliev, M. Molokeev, P. Böni, E. Clementyev. Phys. Rev. B 73, 104401 (2006).

[23] Z.M. Wang, G. Ni, Q.Y. Xu, H. Sang, Y.W. Du. J. Appl. Phys. 90, 5689 (2003).

[24] H. Chen, Ch. Lin, D. Dai. J. Magn. Magn. Mater. 257, 254 (2003).

[25] G.L. Liu, D.A. Zhao, H.Y. Bai, W.H. Wang, M.X. Pan. J. Phys. D 49, 055004 (2016).

[26] А.В. Карташев, И.Н. Флёров, Н.В. Волков, К.А. Саблина. ФТТ 50, 2027 (2008).

[27] Л.Д. Ланлдау, Е.М. Лифшиц. Статистическая физика. Наука, М. (1964). 567 с.

Редактор Т.Н. Василевская 